\title{
A Comparative Study between the Effects of Magnetic and Nonmagnetic Dopants on the Properties of ZnO Varistors
}

\author{
A. Sedky ${ }^{1,2}$ and E. El-Suheel ${ }^{1}$ \\ ${ }^{1}$ Physics Department, Faculty of Science, King Faisal University, P.O. B 400, Al-Hassa 31982, Saudi Arabia \\ ${ }^{2}$ Physics Department, Faculty of Science, Assiut University, Assiut 71516, Egypt \\ Correspondence should be addressed to A. Sedky, sedky1960@yahoo.com
}

Received 3 October 2009; Revised 28 December 2009; Accepted 10 February 2010

Academic Editor: Ali Hussain Reshak

Copyright ( 2010 A. Sedky and E. El-Suheel. This is an open access article distributed under the Creative Commons Attribution License, which permits unrestricted use, distribution, and reproduction in any medium, provided the original work is properly cited.

\begin{abstract}
A comparative study between effects of $\mathrm{Mn}$ and $\mathrm{Al}$ on the properties of $\mathrm{ZnO}$ varistor sintered at $1200^{\circ} \mathrm{C}$ is investigated by $\mathrm{XRD}$, SEM hardness, and I-V measurements. Although both $\mathrm{Mn}$ and $\mathrm{Al}$ do not influence the well-known peaks related to wurtzite structure of $\mathrm{ZnO}$ ceramics, some other unknown peaks could be formed at higher doping content $(\geq 0.10)$. Also, the shape and size of grains are clearly different for both dopants. Average crystalline diameters, deduced from XRD analysis, are between $42 \mathrm{~nm}$ and $62 \mathrm{~nm}$, which are 50 times lower than those obtained from SEM micrographs, while the oxygen vacancies deduced from EDAX analysis, are gradually decreased by doping content for both dopants. Interestingly, the values of breakdown field, nonlinear coefficient and barrier height are found to be higher in Mn samples as compared to $\mathrm{Al}$ samples, while the opposite is reported for leakage currents, hardness, and electrical conductivities. The values of $E_{B}$ are changed from $2.67 \mathrm{~V} / \mathrm{cm}$ to $41.67 \mathrm{~V} / \mathrm{cm} \mathrm{for} \mathrm{Al,} \mathrm{and} \mathrm{from} 1928 \mathrm{~V} / \mathrm{cm}$ to $6571 \mathrm{~V} / \mathrm{cm}$ for $\mathrm{Mn}$. The conductivity of $\mathrm{Al}$ samples is higher than that of $\mathrm{ZnO}$, and it is nearly (103-105) times the conductivity of Mn samples. These results are discussed in terms of the difference of magnetic moment and valence state between these two additives.
\end{abstract}

\section{Introduction}

Zinc oxide varistor is ceramic semiconductor device with nonlinear current-voltage characteristic. Increase of voltage causes the decrease of resistance, and therefore the current is increased strongly. This nonlinear characteristic is symmetrical and it is the same for both voltage polarities [1]. A typical $\mathrm{ZnO}$-based varistor is a very complex chemical system and contains several oxide additives dopants such as $\mathrm{Bi}_{2} \mathrm{O}_{3}$, $\mathrm{Cr}_{2} \mathrm{O}_{3}, \mathrm{Al}_{2} \mathrm{O}_{3}, \mathrm{MnO}, \mathrm{CoO}$, and $\mathrm{Fe}_{2} \mathrm{O}_{3}$ [2-5]. The nonlinear current-voltage characteristics of $\mathrm{ZnO}$ varistors are directly dependent on the composition and microstructure, such as density, grain size, morphology, and distribution of any second phases. By controlling these parameters, the nonlinearity coefficient and the breakdown field of $\mathrm{ZnO}$ varistors may be increased up to 80 and $5000 \mathrm{~V} / \mathrm{cm}$, respectively [2].

The charge transfer mainly controls the electrical conduction in $\mathrm{ZnO}$ varistors during sintering in oxidizing atmosphere [6-9]. The existence of potential barriers across the grain boundaries of $\mathrm{ZnO}$ is confirmed additionally by voltage contrast imaging in the scanning electron microscope (SEM) [10]. At low applied fields, the barrier height is slightly decreased by the field. This is because the electrons capture some increase of the negative interface charge above their absolute value and prevent the sharp barrier lowering. At high field $(\approx 3.2 \mathrm{~V})$ per grain boundary, the barrier height is decreased stronger due to decreasing the negative interface charge than absolute value as a result of holes creation $\left(E_{g}\right.$ $=3.2 \mathrm{eV}$ of $\mathrm{ZnO}$ ) [11]. The appearance of positive charge due to the formation of inversion layer at low fields can lead to the strong increase of the leakage current and helps to explain nonlinear behavior of $\mathrm{ZnO}$ varistors [2]. However, the impact of ionization in the depletion region of grains can give sharp decrease of the barrier height even in the case of thermoionic emission [12].

Earlier, we studied the current-voltage characteristic of $\mathrm{ZnO}$ samples with $\mathrm{Fe}$ as the only magnetic additive and found that samples show significant varistor behavior in both 
quenching and slowly cooled samples $[13,14]$. The addition of Fe improved the nonlinear properties of $\mathrm{ZnO}$ varistor and the electrical barriers could be formed. In the present work, a comparative study between the effects of magnetic (Mn) and nonmagnetic $(\mathrm{Al})$ dopants on the properties of $\mathrm{ZnO}$ is investigated.

\section{Experimental Details}

$\mathrm{Zn}_{1-x} \mathrm{M}_{x} \mathrm{O}$ samples with various $x$ values $(0.00 \leq x \leq 0.20$ $\& \mathrm{M}=\mathrm{Mn}, \mathrm{Al}$ ) are synthesized by using conventional solidstate reaction method [13-15]. The powders of $\mathrm{ZnO} \mathrm{Mn}_{2} \mathrm{O}_{3}$ and $\mathrm{Al}_{2} \mathrm{O}_{3}$ (Aldrich 99.999 purity) are thoroughly mixed in required proportions and calcined at $900^{\circ} \mathrm{C}$ in air for a period of 12 hours. The resulting powders are ground, mixed, and pressed into disks of $1 \mathrm{~cm}$ diameter and $0.3 \mathrm{~cm}$ thick. The pellets are then separately sintered at temperatures of $1200^{\circ} \mathrm{C}$ for 10 hours in air and then quenched down to room temperature. The bulk density of the samples is measured in terms of their weight and volume. The phase purity of the samples is examined by using $\mathrm{X}$-ray diffractmeter with $\mathrm{Cu}$ $\mathrm{K} \alpha$ radiation. Microstructure characterization of the samples is studied by scanning electron microscope (SEM). The Vicker microhardness (VHN) of the samples is determined using an MH-6 digital microhardness tester (0.098-9.8 N). The VHN is estimated according to the following equation: VHN $=0.1891\left(\mathrm{P} / \mathrm{d}^{2}\right)$, where $\mathrm{P}$ is the applied load and $\mathrm{d}$ is the diagonal length of indenter impression. Finally, I$\mathrm{V}$ characteristics are obtained with an electrometer (model 6517 , Keithley), $5 \mathrm{kV}$ dc power supply, and digital multimeter. The samples are well polished and sandwiched between two cupper electrodes and the current is measured relative to the applied voltage at room temperature. High-quality silver paint is used on the samples surfaces for electrical contacts.

\section{Results and Discussion}

It is noted that the color of pure $\mathrm{ZnO}$ and $\mathrm{Al}$ doped samples is white while it changed to brown with low doping of Mn content and it becomes brown with higher doping. The bulk densities of the samples, listed in Table 1, are generally decreased by Mn and increased by Al. It is evident from XRD patterns shown in Figures 1(a) and 1(b) that the structure of $\mathrm{Zn}_{1-x} \mathrm{M}_{x} \mathrm{O}$ samples with $x=0.00,0.025$, and 0.05 is Wurtzite structure, and no additional lines could be formed. When $x$ is increased above 0.05 , some unidentified peaks denoted by stars could be seen in the XRD pattern of both dopants. Furthermore, the intensity of these lines is increased with increasing doping content. Although the number of these unidentified lines is higher for $\mathrm{Mn}$ than $\mathrm{Al}$, the average net intensity is higher for $\mathrm{Al}$ than $\mathrm{Mn}$. This is because with increasing doping content above 0.05 , the solubility limit of dopants through $\mathrm{Zn}$ lattice is reached and some of dopant atoms could be localized at the interstitial position as a secondary lines, as recorded in the XRD patterns. However, the impact of these lines on the nonlinear properties of the considered varistors will be discussed in the next paragraph.
TABLE 1

(a) Density, leakage currents, and nonlinear coefficients of Al-doped $\mathrm{ZnO}$ varistor

\begin{tabular}{lcccc}
\hline Al content & $\rho\left(\mathrm{gm} / \mathrm{cm}^{3}\right)$ & $I_{g}(\mathrm{~A})$ & $\alpha_{1}$ & $\alpha_{3}$ \\
\hline 0.00 & 5.37 & $1.51 \times 10^{-4}$ & 2.04 & 2.09 \\
0.025 & 6.29 & $2.46 \times 10^{-4}$ & 0.21 & 1.63 \\
0.05 & 6.94 & $2.97 \times 10^{-4}$ & 0.24 & 1.43 \\
0.10 & 5.30 & $2.82 \times 10^{-4}$ & 0.22 & 1.47 \\
0.20 & 4.35 & $3.01 \times 10^{-4}$ & 0.09 & 1.61 \\
\hline
\end{tabular}

(b) Density, leakage currents, and nonlinear coefficients of Mn-doped $\mathrm{ZnO}$ varistor

\begin{tabular}{lcccc}
\hline Mn content & $\rho\left(\mathrm{gm} / \mathrm{cm}^{3}\right)$ & $I_{g}(\mathrm{~A})$ & $\alpha_{1}$ & $\alpha_{3}$ \\
\hline 0.00 & 5.37 & $1.51 \times 10^{-4}$ & 2.04 & 2.09 \\
0.025 & 5.16 & $3.32 \times 10^{-5}$ & 1.45 & 1.56 \\
0.05 & 3.88 & $2.91 \times 10^{-5}$ & 1.28 & 2.19 \\
0.10 & 3.76 & $55.5 \times 10^{-4}$ & 0.51 & 1.98 \\
0.20 & 3.77 & $75.6 \times 10^{-4}$ & 0.34 & 1.70 \\
\hline
\end{tabular}

To further confirm that both $\mathrm{Al}^{3+}$ and $\mathrm{Mn}^{3+/ 4+}$ have been substituted for $\mathrm{Zn}^{2+}$ in the cell, are smaller ionic radii of

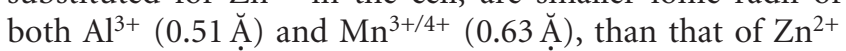
$(0.74 \breve{A})$. The average crystalline diameter $D_{\text {hkl }}$ is evaluated in terms of X-ray line broadening described by the following Scherer's equation [16]:

$$
D_{\mathrm{hkl}}=\frac{k \lambda}{\Delta \theta \cos \theta},
$$

where $\lambda$ is X-ray wavelength $(\lambda=1.5418 \breve{A}), \Delta \theta$ is half maximum line width, $\theta$ is Bragg angle, and $K$ is constant ( $K=0.9$ for this type of ceramics). The average values of

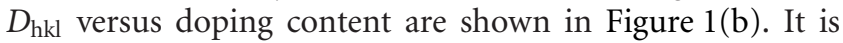
clear that the values of $D_{\mathrm{hkl}}$ are increased by 0.025 of doping content followed by a decrease with an increase up to 0.20 . The values of $D_{\text {hkl }}$ range between $42 \mathrm{~nm}$ up to $62 \mathrm{~nm}$ for all samples.

The microstructure of pure and doped samples is shown in Figure 2(a). Nearly, no second phases are formed at grain boundaries, but the grains are randomly distributed over the matrix structure. Al content up to 0.10 decreased the average grain size as compared to $\mathrm{ZnO}$ sample, and vice versa with higher $\mathrm{Al}$ content while $\mathrm{Mn}$ generally increased the size of grains. The size of black regions is nearly constant and unaffected by the doping. The average grain size, shown in Figure 2(b), indicates that the size of grains decreased by increasing doping content up to 0.05 , followed by an increase up to 0.20 while the size of grains is gradually increased by $\mathrm{Mn}$ addition up to 0.20 and it is higher than that of $\mathrm{Al}$ samples. The sizes of grains, deduced from SEM micrographs, are between $1610 \mathrm{~nm}$ and $3230 \mathrm{~nm}$, which are 50 times higher than those obtained from XRD analysis. Anyhow, it has been reported that diluted magnetic semiconductors are generally formed by partial substitution of n-type $\mathrm{ZnO}$ with small amount of transition metals such 

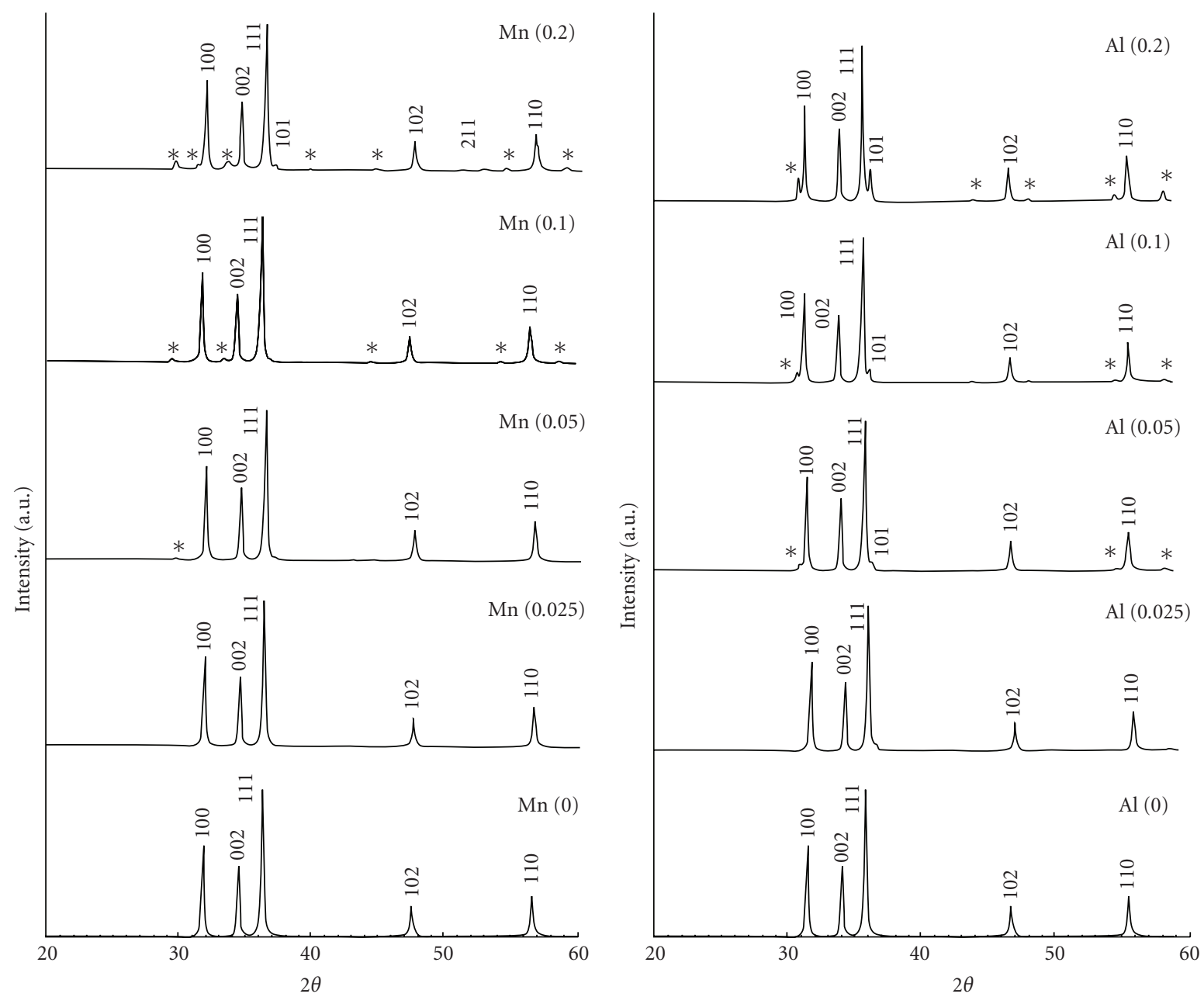

(a)

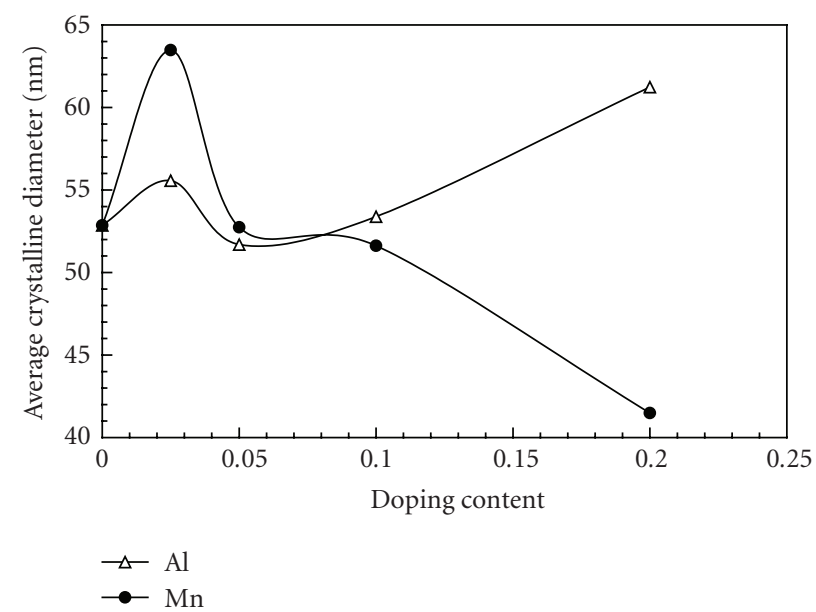

(b)

Figure 1: (a) X-ray diffraction patterns of pure and Mn-doped samples (left) and of pure and Al-doped samples (right). (b) Average crystalline diameter versus doping content for $\mathrm{Al}$ and $\mathrm{Mn}$ samples. 


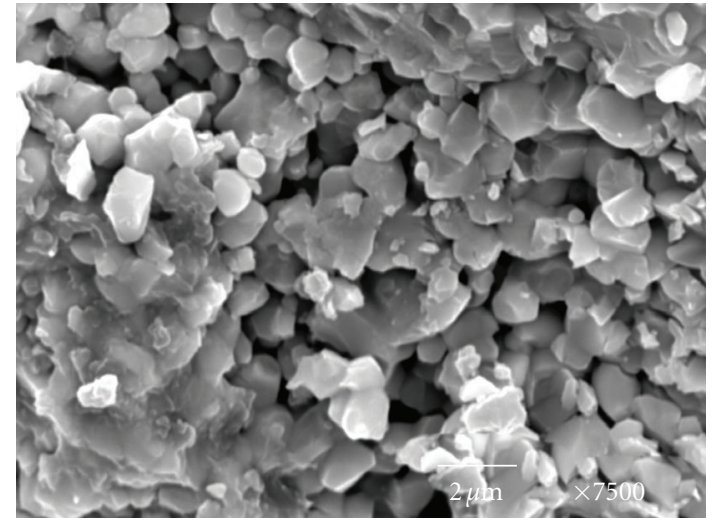

$\mathrm{ZnO}$

(a)

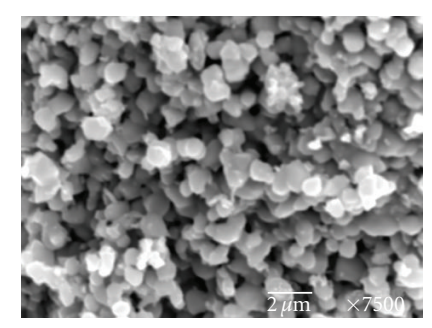

All $(x=0.025)$

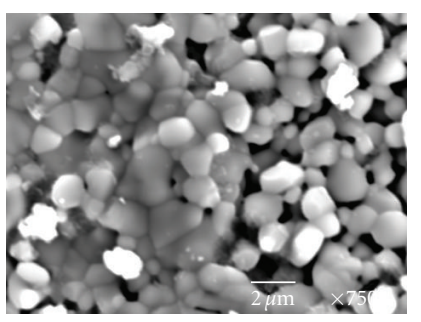

$\operatorname{Mn} 1(x=0.025)$

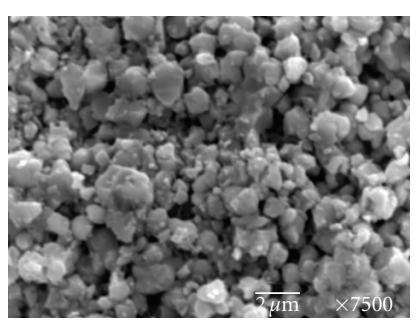

Al2 $(x=0.05)$

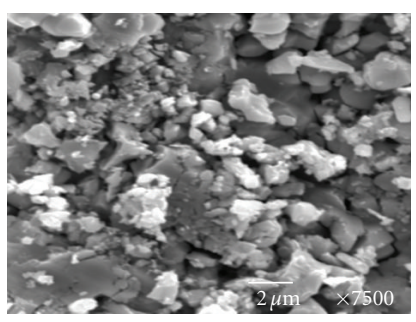

$\operatorname{Mn} 2(x=0.05)$

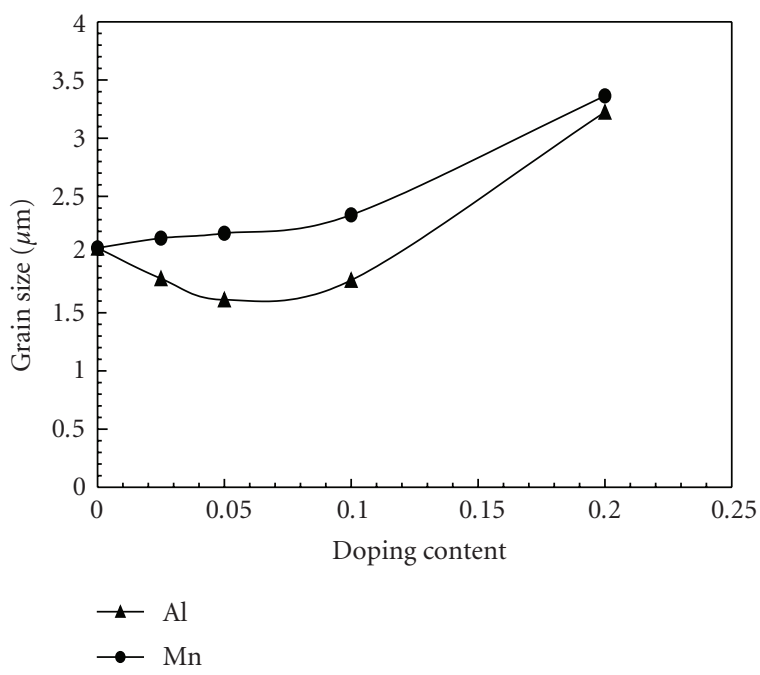

(b)

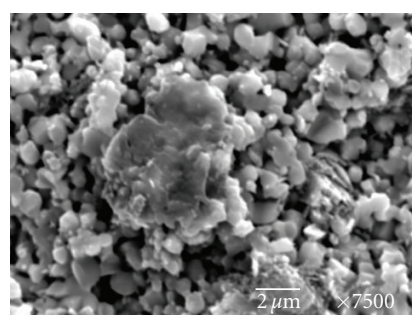

$\operatorname{Al3}(x=0.1)$

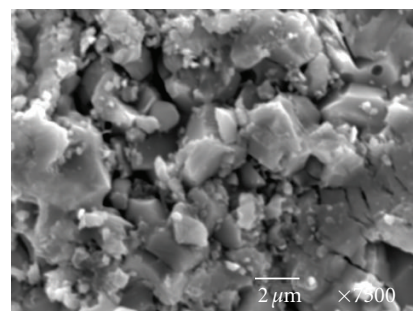

$\operatorname{Mn} 3(x=0.1)$

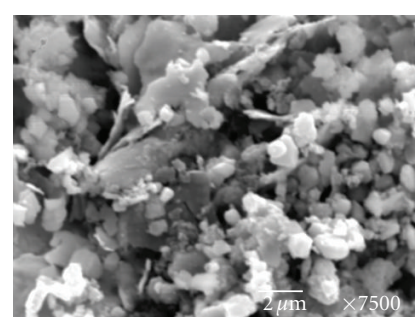

$\mathrm{Al} 4(x=0.2)$

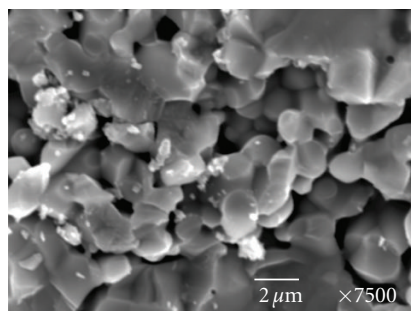

$\operatorname{Mn} 4(x=0.2)$ 


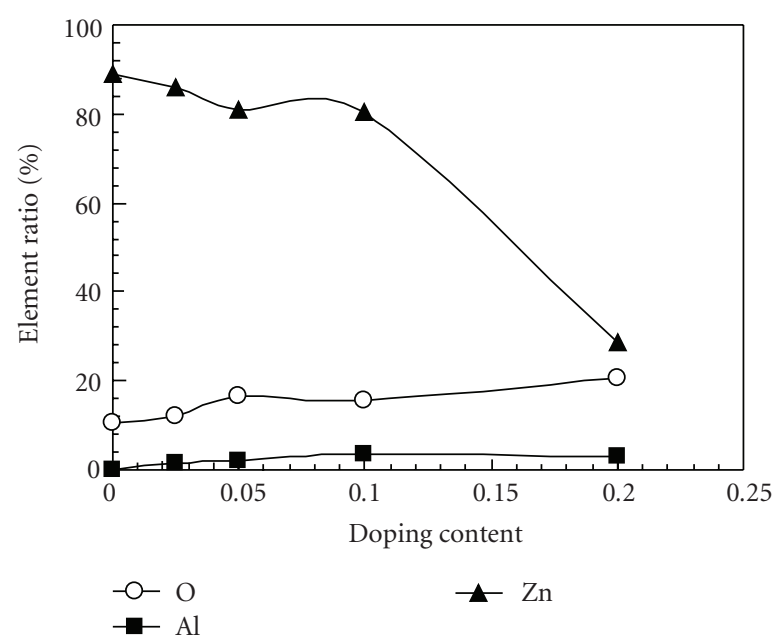

(c)

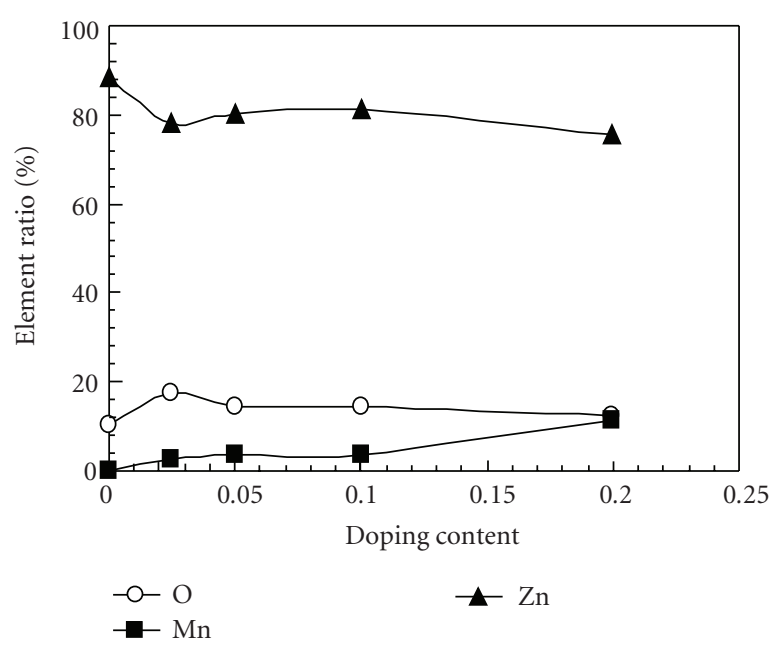

(d)

FIgURe 2: (a) SEM micrographs for pure and doped ZnO samples. (b) Grain size for Pure and Al-doped ZnO samples. (c) Element ratio for Pure and $\mathrm{Al}$ doped $\mathrm{ZnO}$ samples. (d) Element ratio for Pure and $\mathrm{Mn}$-doped $\mathrm{ZnO}$ samples.

as $\mathrm{Mn}$ and Ni. In such samples, TEM data show that most of the particles size is around $60 \mathrm{~nm}$ [16]. These data support the values of average grain size deduced from XRD analysis rather than those obtained from SEM micrograph. Since HR/SEM and TEM techniques are not available for us at present, this will be taken into consideration for further research. The elements ratio as a function of doping content is shown in Figures 2(b) and 2(c). It is clear that the element ratios of both dopants are decreased while it is slightly increased for oxygen. This means that the oxygen vacancies are slightly decreased by the dopants.

There are three different regions observed in the I-V curves of the samples shown in Figures 3(a) and 3(b). The first and third regions are nearly ohmic behavior, while the other is clearly nonlinear behavior (upturn region). The values of applied fields at the boundary of the nonlinear region are shifted to lower values by $\mathrm{Al}$ addition, and vice versa for Mn-doped samples, while the values of current density are generally increased by $\mathrm{Al}$ and decreased by $\mathrm{Mn}$. However, the important parameter, $E_{B}$, breakdown field is usually taken as the field applied when the current flowing through the varistor is $1 \mathrm{~mA} / \mathrm{cm}^{2}[17,18]$. The variation of $E_{B}$, obtained from dc electrical measurements, versus doping content is shown in Figure 3(c). It is clear that $\mathrm{Al}$ content up to 0.05 decreased $E_{B}$, followed by an increase with increasing $\mathrm{Al}$ up to 0.20 while $E_{B}$ is increased by increasing $\mathrm{Mn}$ up to 0.20 . The highest value of $E_{B}$ for $\mathrm{Mn}(6571 \mathrm{~V} / \mathrm{cm})$ is approximately $1.5 \times 10^{2}$ times the highest value of $E_{B}$ for $\operatorname{Al}(41.67 \mathrm{~V} / \mathrm{cm})$. The values of $E_{B}$ range between $2.67 \mathrm{~V} / \mathrm{cm}$ and $41.67 \mathrm{~V} / \mathrm{cm}$ for $\mathrm{Al}$, and it is varied from $1928 \mathrm{~V} / \mathrm{cm}$ up to $6571 \mathrm{~V} / \mathrm{cm}$ for $\mathrm{Mn}$. These results indicate that $E_{B}$ could be increased up to $6571 \mathrm{~V} / \mathrm{cm}$ by 0.1 of $\mathrm{Mn}$ doping, which is higher than that reported for $\mathrm{ZnO}$ varistor $(5000 \mathrm{~V} / \mathrm{cm})$ [2].
The current-voltage relation of a varistor is given by the following equation $[17,18]$ :

$$
J=\left(\frac{E}{C}\right)^{\alpha}
$$

where $J$ is the current density, $E$ is the applied electric field, $C$ is a proportionality constant corresponding to the resistance of ohmic resistor (nonlinear resistance), and $\alpha$ is the nonlinear coefficient. The current-voltage curves are plotted on a log-log scale, from which the slope of the curve gives the value of $\alpha[19,20]$. The values of $\alpha$ are obtained across the first and third regions and listed in Table 1, while the variation of $\alpha$ against doping content in the nonlinear region is shown in Figure 3(d). It is apparent that $\alpha$ decreases by Mn doping content up to 0.05 , followed by an increase up to 0.20 . The values of $\alpha$ are decreased by $\mathrm{Al}$ doping and remain lower than the undoped sample, while the values of $\alpha$ at higher doping of Mn doping (0.10 and 0.20) become higher than the undoped sample. From these results, it is determined that the addition of low amount of $\mathrm{Al}^{3+}$ oxide to $\mathrm{ZnO}$ varistor composition decreased the nonohmic features and shifted the breakdown fields to lower values. while the addition of $\mathrm{Mn}^{3+/ 4+}$ doping generally improved the nonlinear behavior and shifted the breakdown field to higher values. On the other hand, the leakage current $I_{k}$ is the current value, which corresponds to a field equal to half $E_{B}$. These calculations enable us to study the I-V characteristics in the ohmic region as compared to upturn region $[1,6,21]$. When the $\mathrm{Al}$ content increases, the low current region goes up and the leakage current, listed in Table 1, slightly increases. The opposite is reported for higher Mn-doped samples. But the increments of the leakage currents are higher in the $\mathrm{Al}$-doped samples than $\mathrm{Mn}$ samples. 


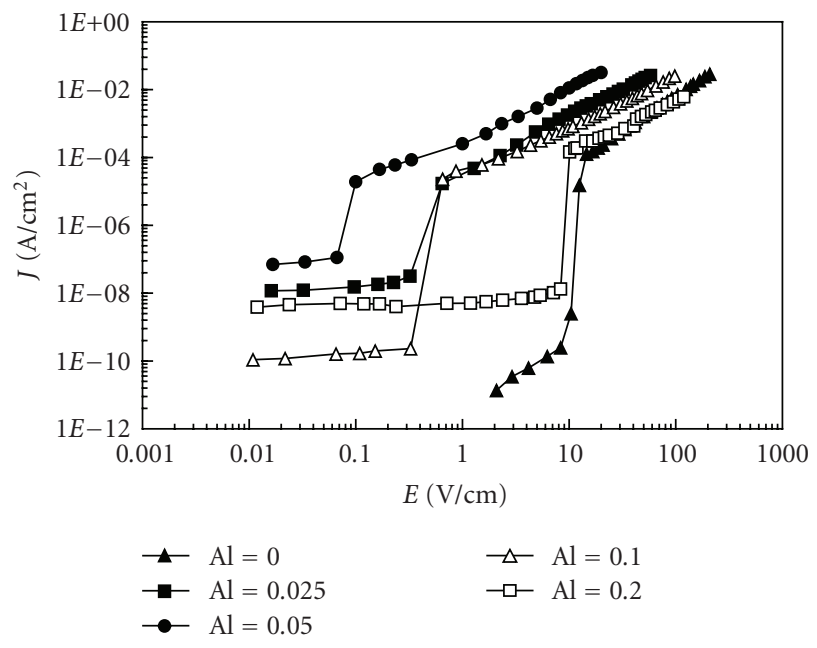

(a)

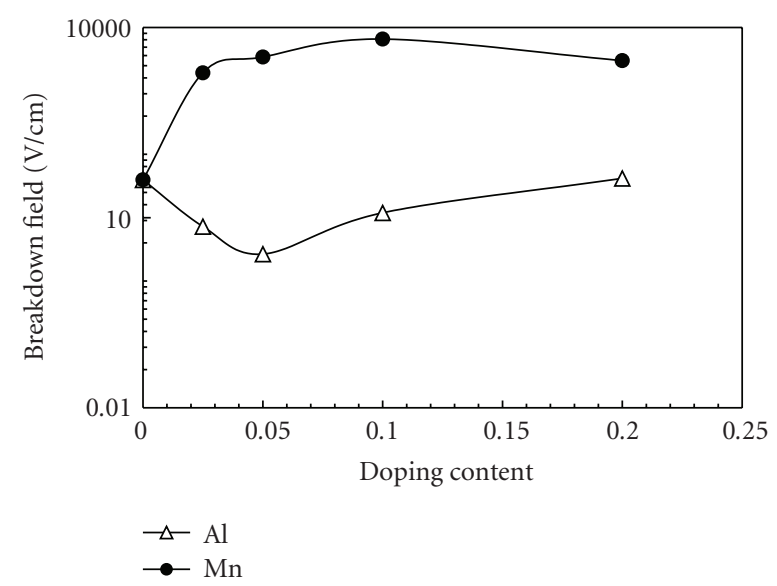

(c)

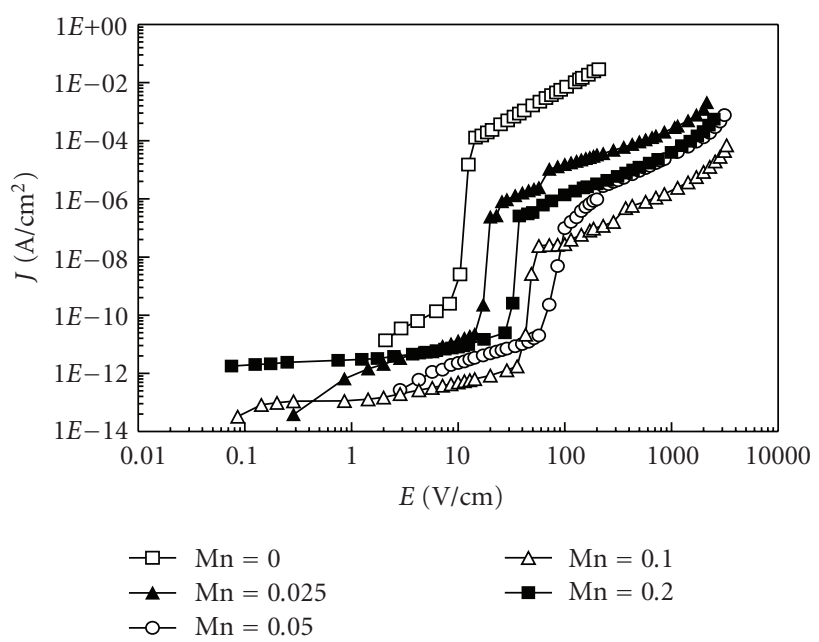

(b)

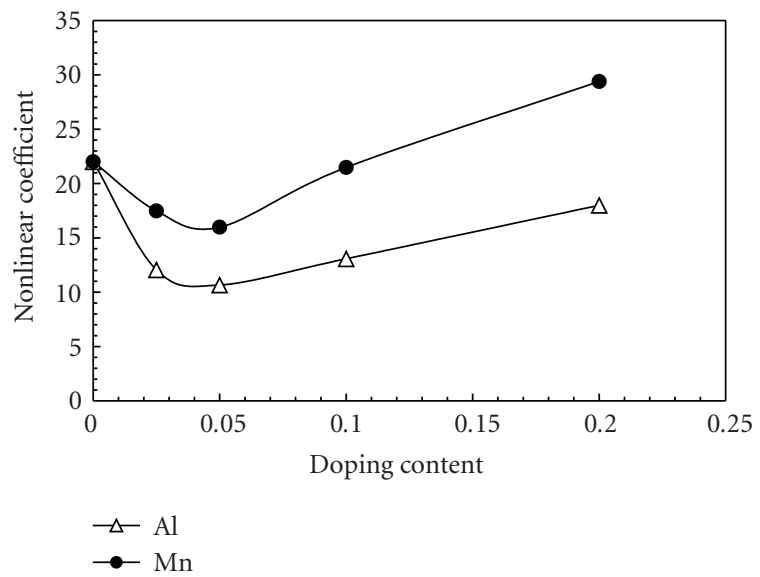

(d)

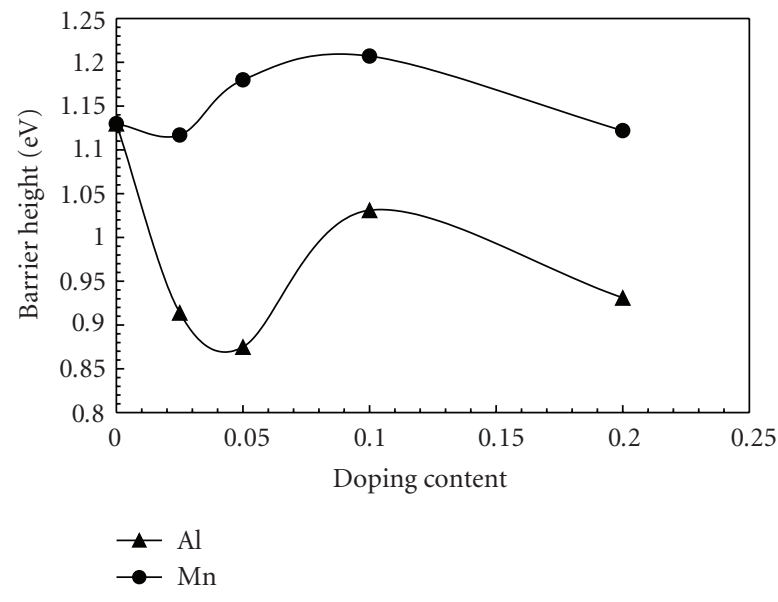

(e)

Figure 3: (a) I-V characteristics for Pure and $\mathrm{Al}$ doped $\mathrm{ZnO}$ samples. (b) I-V characteristics for Pure and Mn doped $\mathrm{ZnO}$ samples. (c) Breakdown field for Pure and doped ZnO samples. (d) Nonlinear coefficient for Pure and doped ZnO samples. (e) Barrier height for Pure and doped $\mathrm{ZnO}$ samples. 


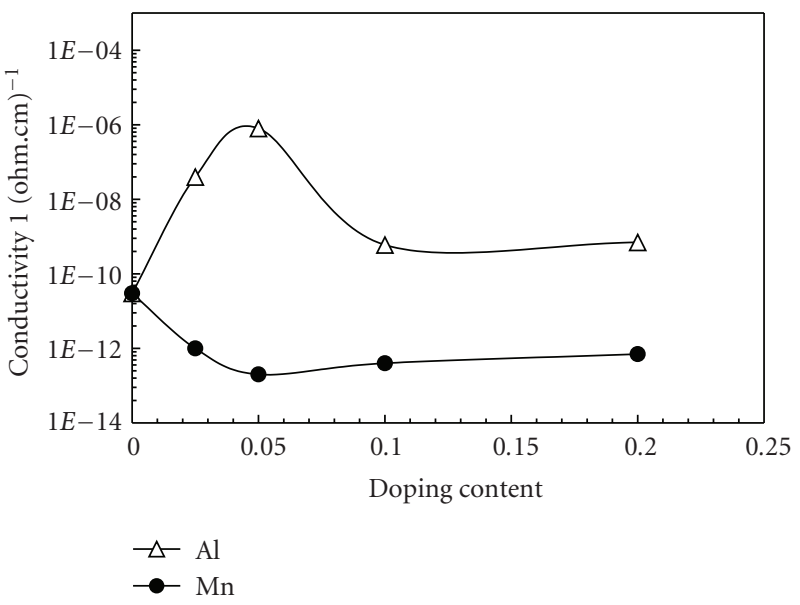

(a)

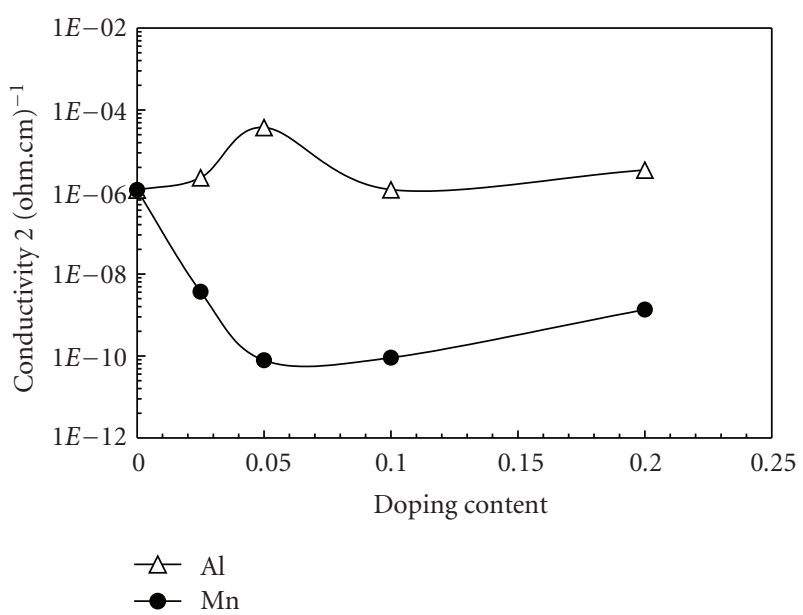

(b)

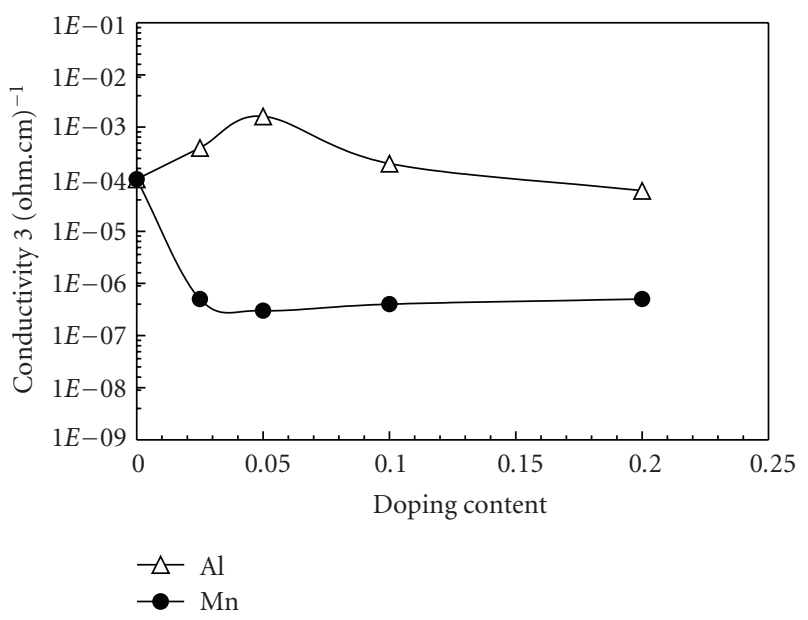

(c)

FIGURE 4: (a) Electrical conductivity across the first region for pure and doped $\mathrm{ZnO}$ samples. (b) Electrical conductivity across the nonlinear region for Pure and doped $\mathrm{ZnO}$ samples. (c) Electrical conductivity across the third region for Pure and doped $\mathrm{ZnO}$ samples.

Since Schottky type grain boundary barriers exist in the present samples, the current density in the ohmic region of varistor is related to the applied electric field by the following formula $[13,17]$ :

$$
J=A T^{2} \exp \left[\frac{\beta E^{1 / 2}-\varphi_{B}}{k T}\right],
$$

where $A$ is Richardson's constant $\left\{A=\left(4 \rho e m K^{2} / h^{3}\right)\right\}$, $\rho$ is the varistor density, $e$ is the electronic charge, $m$ is the electronic mass, $k$ is the Boltzmann constant, $h$ is Planck's constant, $\varphi_{B}$ is the interface barrier height, and $\beta$ is a constant. By measuring the current density in the ohmic region and keeping the temperature constant, for two different roots of applied fields, the values of $\varphi_{B}$ could be obtained. The variation of $\varphi_{B}$ against doping content shown in Figure 3(e) indicates that $\varphi_{B}$ decreases by $\mathrm{Al}$ up to 0.05 , followed by an increase at 0.10 , and again decreased at 0.20 , while $\varphi_{B}$ is generally increased by Mn-doping. This behavior is nearly consistent with the behaviors of nonlinear coefficient and breakdown field. These results support the improvements of electrical barriers in the Mn doped samples as compared to both undoped and $\mathrm{Al}$-doped samples.

In $\mathrm{ZnO}$ varistors, free electrons can be released and raise the conductivity $\sigma$ by increasing the density of electron which are considered to be the majority carriers. In the present case, $\sigma$ is calculated from the $(J / E)$ in the first and third regions (ohmic regions), while, in the second region (nonlinear region), the currents strongly increase due to the decrease of $\varphi_{B}$. Then, the conductivity in the nonlinear region is given by [22]

$$
\sigma_{2}=\sigma_{1} \exp \left\{\frac{(\alpha-1)\left(E_{2}-E_{1}\right)}{E_{2}}\right\},
$$

where $\sigma_{1}$ is the conductivity in the low field region (first region). $E_{1}$ and $E_{2}$ are the applied fields across the nonlinear region. Figures $4(\mathrm{a})-4$ (c) show the dc electrical conductivity as a function of doping content across the three different regions. It is observed that the conductivity, as compared to undoped sample, generally decreases by Mn addition and increased by Al. Anyhow, the conductivity curves shown in 


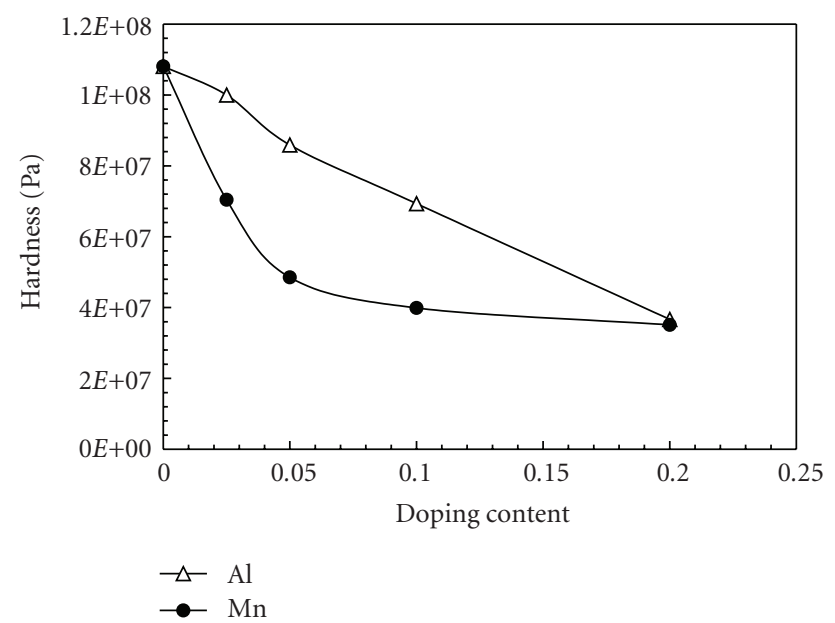

Figure 5: Hardness at $0.98 \mathrm{~N}$ for Pure and doped $\mathrm{ZnO}$ samples.

Figure 4 could be divided into two regions as follows: the first region at low doping content $(0.00 \leq x \leq 0.05)$, in which the conductivity is increased by $\mathrm{Al}$ and decreased by $\mathrm{Mn}$; and the second region where $(0.10 \leq x \leq 0.2)$, in which the conductivity is nearly unchanged by $\mathrm{Al}$ and increased by $\mathrm{Mn}$. But the values of conductivity remain higher for $\mathrm{Al}$ than Mn. There are possible factors other than the presence of the second phases, which should be responsible for the reduction of conductivity by $\mathrm{Mn}$ doping. This is because these second phases are due to the solubility limit of doping through the $\mathrm{ZnO}$ lattice. Therefore, we believe that when $\mathrm{Mn}$ is dissolved in $\mathrm{ZnO}$, it behaves as a deep donor and depresses the concentrations of the intrinsic donors at the sintering temperature. When the samples are quenched, the concentrations of these intrinsic donors at room temperature are also lowered. In this way, the conductivity, mainly arising from the ionization of intrinsic donors, is lowered by the presence of low Mn doping content. With increasing Mn content $(0.10 \leq \mathrm{Mn} \leq 0.2)$, the solubility limit of $\mathrm{Mn}$ through the interstitial position, in which $\mathrm{Mn}$ also behaves as an acceptor, exceeds the donor effect and increased the conductivity [23], so, the solubility limit of Mn through $\mathrm{Zn}$ lattice is responsible for increasing conductivity at higher content, while the mechanism of $\mathrm{Al}$ reaction with $\mathrm{Zn}$ in the structure could be described as follows [24, 25].

Neutral Zn interstitial zinc atom is firstly ionized as

$$
\begin{aligned}
& \mathrm{Zn} \longrightarrow \mathrm{Zn}^{+}+\mathrm{e} \text {, and secondly ionized as } \\
& \mathrm{Zn}^{+} \longrightarrow+\mathrm{Zn}^{++}+\mathrm{e} .
\end{aligned}
$$

Such free electrons move to the conduction band of $\mathrm{ZnO}$ and enhance the conductivity of $\mathrm{ZnO}$. The conductivity of $\mathrm{ZnO}$ can also be increased by extrinsic defects at $\mathrm{Zn}$ site such as $\mathrm{Al}^{3+}$. In $\mathrm{Zn}^{2+}$ substituted with $\mathrm{Al}^{3+}$, some of free electrons are released and raise the conductivity of $\mathrm{ZnO}$ at low values of $\mathrm{Al}$ content $(0.00 \leq \mathrm{Al} \leq 0.1)$. With increasing $\mathrm{Al}$ content $(0.10 \leq \mathrm{Al} \leq 0.2)$, the solubility limit of Al through the interstitial position, in which $\mathrm{Al}$ also behaves as an acceptor may be equalize the donor effect and keeps the conductivity nearly unchanged.
Figure 5 demonstrates the Vickers microhardness (VHN) plotted as a function of doping content at $0.98 \mathrm{~N}$-applied load. An approximately monotonically linear decrease in VHN with increasing doping content up to 0.20 is observed. This means that the substitution up to 0.20 can substantially suppress microcracking of $\mathrm{ZnO}$ ceramics and consequently VHN is decreased. This is probably attributed to weakness of the coupling between the grains and elimination of pores, which may occur by the doping during heat treatments. Then, one can say that the mechanical resistance becomes lower and consequently the mechanical connection is depressed. These results are consistent with SEM photographs where the grains are not close together through the weak link regions. The dark regions between the grains indicate a weak link between them. The question is why the values of $\mathrm{VHN}$ for $\mathrm{Al}$ remain higher than the values of $\mathrm{VHN}$ for Mn. This may be related to the difference in the values of density and grain size between the two dopants.

It is evident from the above results that $\mathrm{Al}$ generally leads to break the formation of potential barrier in the grain boundary of $\mathrm{ZnO}$ varistor, and consequently both breakdown field and nonlinear coefficient are decreased, While the electrical conductivity is apparently higher than that of the undoped $\mathrm{ZnO}$, indicating that the grain boundary is less resistive than the grains. In contrast, the Mn doping leads to supporting the formation of the potential barrier in the grain boundary, and consequently both breakdown field and nonlinear coefficient are enhanced, whereas the electrical conductivity is apparently lower than that of the undoped $\mathrm{ZnO}$, indicating that the grain boundary is more resistive than the grains. It is well known that $\mathrm{Zn}^{2+}$ and $\mathrm{Al}^{3+}$ are nonmagnetic ions and $\mathrm{Mn}$ is magnetic ion with $4.9 \mu_{B}$ magnetic moment. Furthermore, the higher valence state of $\mathrm{Mn}^{3+/ 4+}$ than $\mathrm{Al}^{3+}$ may lead to the formation of acceptor levels and make the grain boundary region more resistive. So, we believe that both valence state and magnetic moment of the two considered dopants are responsible for the observed difference in the behaviors of electrical properties between them.

\section{Conclusion}

A comparative study between effects of $\mathrm{Mn}$ and $\mathrm{Al}$ on the properties of $\mathrm{ZnO}$ varistor is investigated. We have shown that both $\mathrm{Mn}$ and $\mathrm{Al}$ do not influence the well-known peaks related to wurtzite structure of $\mathrm{ZnO}$ ceramics, while, the shape and size of grains and oxygen vacancies are clearly effected by the doping addition and they are different for both dopants. Interestingly, the values of breakdown field, nonlinear coefficient, and barrier height are found to be higher for $\mathrm{Mn}$ samples as compared to $\mathrm{Al}$ samples, and the opposite, holds for leakage currents, hardness and electrical conductivities. We could increase $E_{B}$ up to 6571 by 0.10 of $\mathrm{Mn}$ addition to $\mathrm{ZnO}$. Furthermore, the $\mathrm{Al}$ addition could increase the conductivity up to three times the conductivity of $\mathrm{ZnO}$, and it is approximately $\left(10^{3}-10^{5}\right)$ times the conductivity of Mn samples. Our results show that the valence state and magnetic moment of the considered 
dopants are responsible for the observed difference in the behaviors of electrical properties between them.

\section{References}

[1] T. K. Gupta, "Application of zinc oxide varistors," Journal of the American Ceramic Society, vol. 73, no. 7, pp. 1817-1840, 1990.

[2] A. B. Glot, "A model of non-Ohmic conduction in $\mathrm{ZnO}$ varistors," Journal of Materials Science: Materials in Electronics, vol. 17, no. 9, pp. 755-765, 2006.

[3] A. M. R. Senos, M. R. Santos, A. P. Moreira, and J. M. Vieira, "Grain boundary phenomena in the early stages of sintering of MO oxides," in Surface and Interfaces of Ceramic Materials, L. C. Dufour, C. Monty, and G. Petot-Ervas, Eds., NATO ASI Series, pp. 553-563, Kluwer Academic, London, UK, 1988.

[4] A. M. R. Senos and J. M. Vieira, "Pore size distribution and particle rearrangement during sintering," in Proceedings of the 3 rd International Conference on Euro-Ceramics, P. Duran and J. F. Fernandez, Eds., vol. 1, pp. 821-826, Faenza Edit rice Iberica S. L., Faenza, Italy, 1993.

[5] A. M. R. Senos, Sintering kinetics in open porosity stages of zinc oxide, Ph.D. thesis, University of Aveiro, Aveiro, Portugal, 1993.

[6] S. Levine, "Theory of varistor electronic properties," Critical Reviews in Solid State and Materials Sciences, vol. 5, no. 4, pp. 597-608, 1975.

[7] J. Bwrnasconi, S. Strässler, B. Knecht, H. P. Klein, and A. Menth, "Zinc oxide based varistors: a possible mechanism," Solid State Communications, vol. 21, no. 9, pp. 867-870, 1977.

[8] R. Einzinger, "Grain junction properties of $\mathrm{ZnO}$ varistors," Applications of Surface Science, vol. 3, no. 3, pp. 390-408, 1979.

[9] A. M. R. Senos and J. L. Baptista, "Atmosphere effects in the grain boundary region of $\mathrm{ZnO}$ varistors," Journal of Materials Science Letters, vol. 3, no. 3, pp. 213-216, 1984.

[10] A. B. Glott, C. A. Hogarth, and R. Bulpett, "Voltage contrast imaging of zinc oxide ceramics," International Journal of Electronics, vol. 65, no. 4, pp. 797-804, 1988.

[11] G. D. Mahan, L. M. Levinson, and H. R. Philipp, "Theory of conduction in $\mathrm{ZnO}$ varistors," Journal of Applied Physics, vol. 50, no. 4, pp. 2799-2812, 1979.

[12] G. E. Pike, "Electonic properites of $\mathrm{ZnO}$ varistors: a new model," in Materials Research Society Symposia Proceedings: Grain Boundaries in Semiconductors, G. E. Pike, C. H. Seager, and H. J. Leamy, Eds., vol. 5, p. 369, Elsevier, New York, NY, USA, 1982.

[13] A. Sedky, M. Abu-Abdeen, and A. A. Almulhem, "Nonlinear $\mathrm{I}-\mathrm{V}$ characteristics in doped $\mathrm{ZnO}$ based-ceramic varistor," Physica B, vol. 388, no. 1-2, pp. 266-273, 2007.

[14] A. Sawalha, M. Abu-Abdeen, and A. Sedky, "Electrical conductivity study in pure and doped $\mathrm{ZnO}$ ceramic system," Physica $B$, vol. 404, no. 8-11, pp. 1316-1320, 2009.

[15] M. S. Castro and C. M. Aldao, "Effects of the sintering temperature on the oxygen adsorption in $\mathrm{ZnO}$ ceramics," Journal of the European Ceramic Society, vol. 19, no. 4, pp. 511$515,1999$.

[16] G. Pei, C. Xia, S. Cao, J. Zhang, F. Wu, and J. Xu, "Synthesis and magnetic properties of Ni-doped zinc oxide powders," Journal of Magnetism and Magnetic Materials, vol. 302, no. 2, pp. 340342, 2006.

[17] V. V. Deshpande, M. M. Patil, and V. Ravi, "Low voltage varistors based on $\mathrm{CeO}_{2}$," Ceramics International, vol. 32, no. 1, pp. 85-87, 2006.
[18] M. Houabes, S. Bernik, C. Talhi, and A. Bui, "The effect of aluminium oxide on the residual voltage of $\mathrm{ZnO}$ varistors," Ceramics International, vol. 31, no. 6, pp. 783-789, 2005.

[19] M. Matsuoka, "Nonohmic properties of Zinc oxide ceramics," Japanese Journal of Applied Physics, vol. 10, no. 6, pp. 736-746, 1971.

[20] J. Han, P. Q. Mantas, and A. M. R. Senos, "Defect chemistry and electrical characteristics of undoped and Mn-doped $\mathrm{ZnO}$," Journal of the European Ceramic Society, vol. 22, no. 1, pp. 49 59,2002

[21] T. Takemura, M. Kobayashi, Y. Takada, and K. Sato, "Effects of antimony oxide on the characteristics of $\mathrm{ZnO}$ varistors," Journal of the American Ceramic Society, vol. 70, no. 4, pp. 237241, 1987.

[22] A. Sedky, under submission to New Journal of Physics.

[23] J. Han, P. Q. Mantas, and A. M. R. Senos, "Effect of A1 and Mn doping on the electrical conductivity of $\mathrm{ZnO}$," Journal of the European Ceramic Society, vol. 21, no. 10-11, pp. 1883-1886, 2001.

[24] T. K. Gupta, "Microstructural engineering through donor and acceptor doping in the grain and grain boundary of a polycrystalline semiconducting ceramic," Journal of Materials Research, vol. 7, no. 12, pp. 3280-3295, 1992.

[25] M. Houabes, S. Bernik, C. Talhi, and A. Bui, "The effect of aluminium oxide on the residual voltage of $\mathrm{ZnO}$ varistors," Ceramics International, vol. 31, no. 6, pp. 783-789, 2005. 

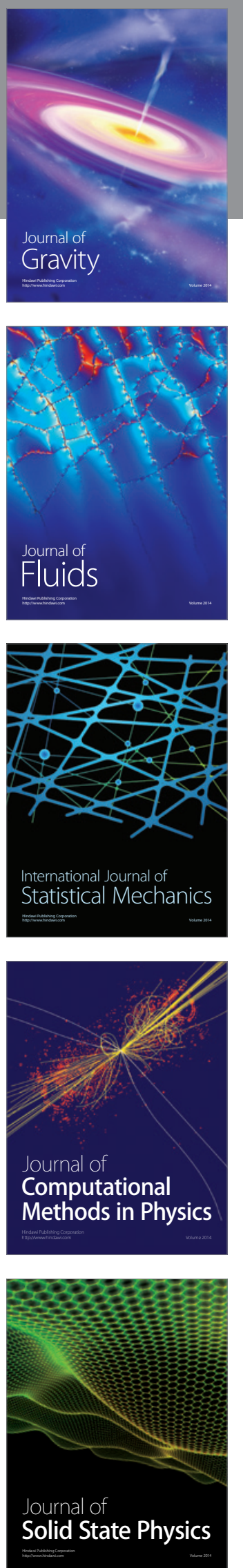

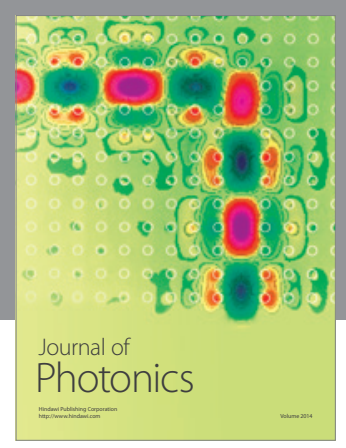

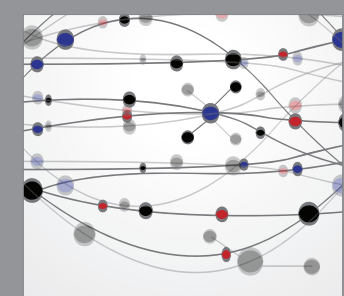

The Scientific World Journal
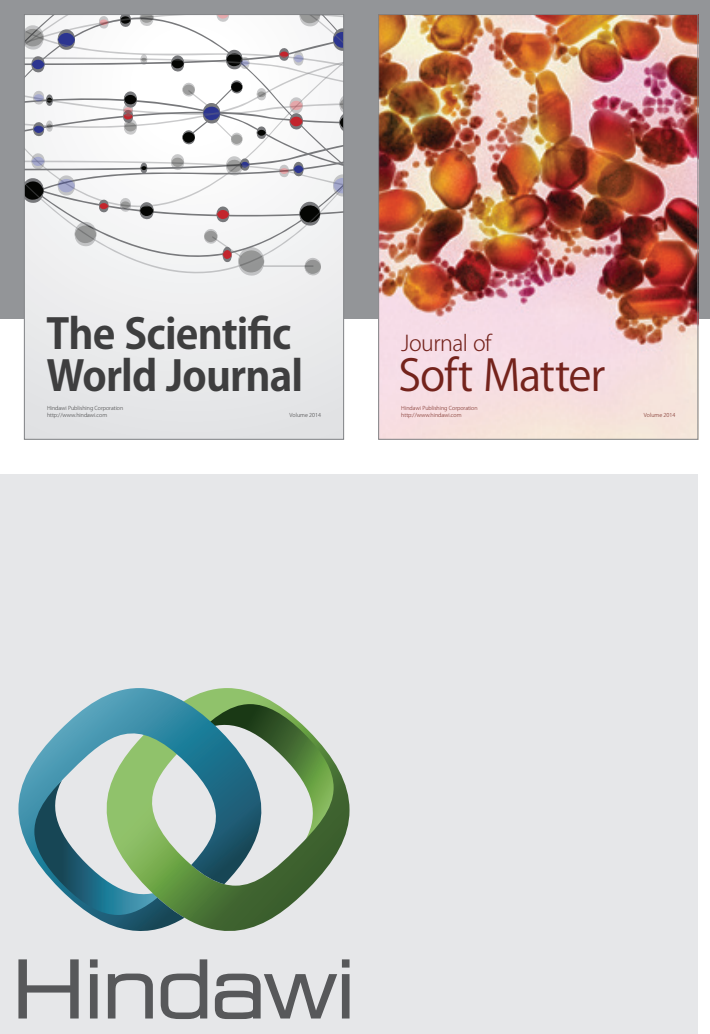

Submit your manuscripts at

http://www.hindawi.com
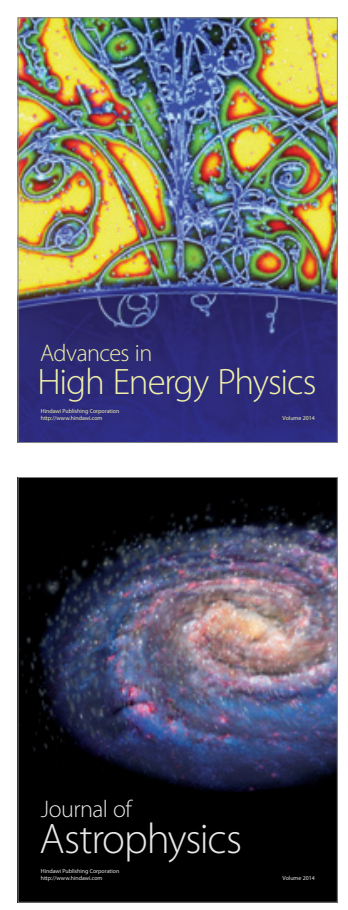
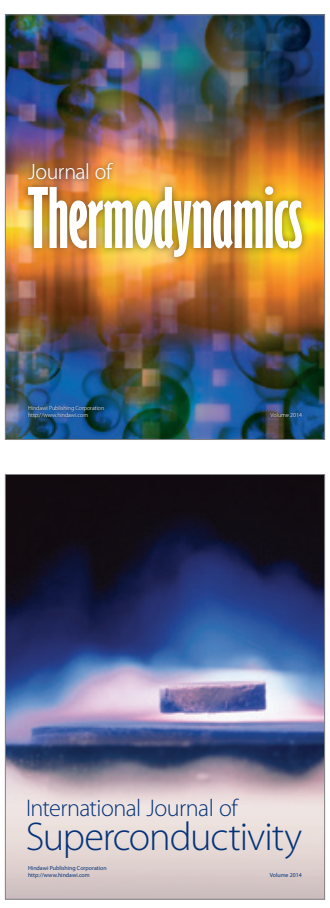
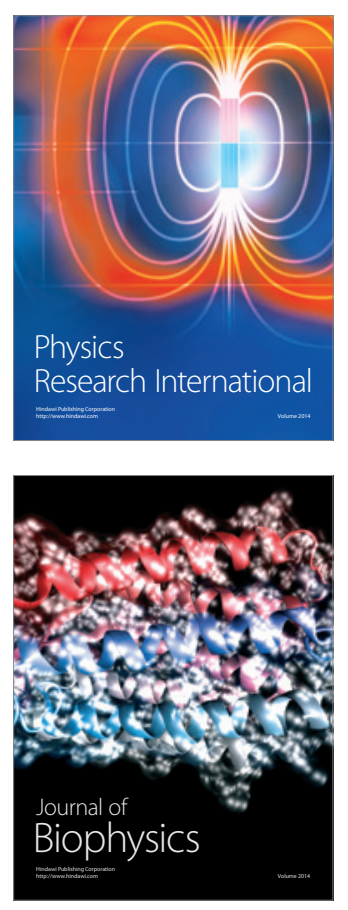
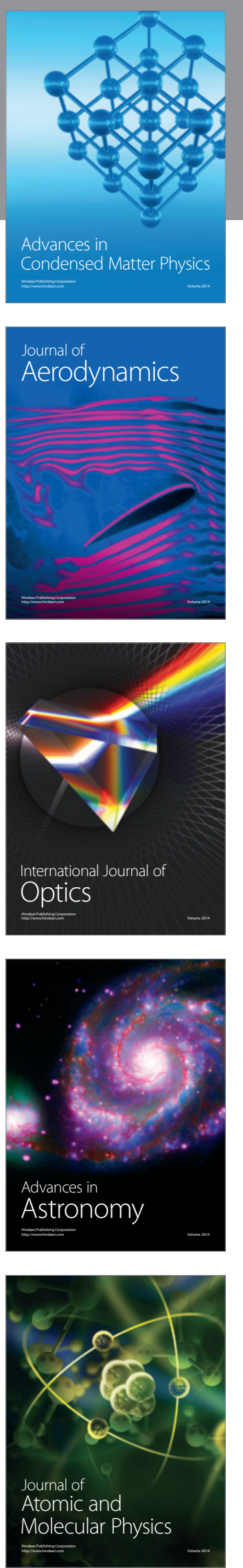